\title{
PATIENT-REPORTED OUTCOMES - AN APPROACH AND APPLICATION IN AMNIOTIC MEMBRANE TRANSPLANTATION
}

\author{
Yana Manolova ${ }^{1}$, Desislava Vankova ${ }^{2}$, Christina Grupcheva ${ }^{1}$ \\ ${ }^{1}$ Department of Ophthalmology and Visual Science, Faculty of Medicine, \\ Medical University of Varna \\ ${ }^{2}$ Department of Social Medicine and Health Care Organization, Faculty of Public Health, \\ Medical University of Varna
}

\begin{abstract}
Patient-reported outcomes (PROs) are a comparatively novel concept in medicine and in public health services evaluation. It relies on the fact that medical technologies are not able to give all the information about the treatment or a medical condition. Some essential data can be obtained only from the patient.

Herewith, the PROs approach is presented in relation to amniotic membrane transplantation (AMT) which is applied to patients who have been treated at Varna Specialized Eye Hospital for different severe anterior ocular surface diseases (AOSDs).

The aim of the study is to present the PROs approach and the created especially for the study Patient-Reported Outcome Measures (PROMs) tool. Further on, we aim to summarize, analyze and discuss the PROsdata of the study.

MATERIALS AND METHODS: The presented PROs study enrolls 306 hospitalized patients diagnosed in seven cohorts and suitable for AMT for a period of seven years (2010-2016). It is a part of a wider research project. Demographic data and disease-related characteristics were collected in addition to the PROMs questionnaire. The PROMs instrument consists of 4 domains/questions, and the possible answers are arranged in ordinal scales. The first domain is Pain, and the possible answers are 5 ( 0 - none; 1 - sometimes low; 2 always low; 3 - moderate to severe; 4 - always severe). The second domain is Photophobia, and the possible answers are 4 (0 - none; 1 - only at strong light; 2 - at daylight; 3 - at moderate light). The third domain is Secretion and the possible answers are 4 ( 0 - none; 1 - watery; 2 - mucous secretion; 3 - purulent discharge). The fourth domain is Hyperemia and the possible answers following the Efron grading scale are 5 (grade 0 - normal; grade 1 - trace; grade 2 - mild; grade 3 - moderate; grade 4 - severe).

RESULTS AND DISCUSSION: The AM treatment resulted in a significant reduction of the symptoms in all domains $(\mathrm{p}<0.001)$. Regarding the Pain domain, in all the groups, over $60 \%$ of the patients reported improvement. More than $\mathbf{9 0 \%}$ of the patients with the most severe conditions like keratitis reported improvement. The reported and analyzed results indicate that AMT has a positive impact on all the PROs do-

Address for correspondence:

Yana Manolova

Specialized Eye Hospital

15 Doyran St

Varna, 9000

e-mail:y.m.manolova@gmail.com

Received: February 22, 2017

mains - Pain, Photophobia, Secretion and Hyperemia, for every patient $(\mathrm{p}<\mathbf{0 . 0 0 1})$. This is a novel study for Bulgaria, which aims to measure the impact of AMT on PROs among a large number of patients with severe AOSDs divided into seven cohorts for seven years. AMT proved to be a surgical method for treatment of chronic, recurrent AOSDs that improve patients' subjective well-being.
\end{abstract}

Accepted: March 14, 2017 
Patient-Reported Outcomes - an Approach and Application in Amniotic Membrane Transplantation

Keywords: patient-reported outcomes and measures, amniotic membrane transplantation

\section{INTRODUCTION}

Patient-reported outcomes (PROs)

Medicine as a science and practice has changed tremendously during the last centuries but the human nature of the healing art has always been the care for the patient. In 1863, the legendary Florence Nightingale in her "Notes on Hospitals" (1) summarized "seven elements", which are essential while evaluating the success of the curative process. One of these criteria is if the patient is "recovered or relieved" as a result of the hospital experience. During the years the importance of the subjective criteria in clinical medicine and in public health has increased. In 2009, the US Food and Drug Administration (FDA) (2) recommended that PROs be used as a desirable endpoint in the medical product development. Even though innovative technologies allow the measuring of physical, physiological or biochemical data of the patient, they are not able to provide all the data about the treatment or the disease. Some essential data can be obtained only from the patient.

May be the most famous definition of a "health outcome" is that of Donabedian (3) which states that a health outcome is the change of the current and the future health status of the patient that might be due to prior health care, including medication or surgery. FDA defines PROs as any report of the status of a patient's health condition that comes directly from the patient, without an interpretation of the patient's response by a clinician or anyone else. The outcome can be measured in absolute terms (e.g. severity of a symptom, sign, or state of a disease) or as a change from a previous measure.

Patient-Reported Outcome Measures (PROMs) are tools and/or instruments used to report PROs. Therefore, PROMs (i.e. a questionnaire plus the information and documentation that support its use) are a means to capture PROs data used to measure treatment benefit, risk in medical product clinical trials or public health services evaluation.

Amniotic membrane transplantation (AMT) is a surgical treatment, which could be successfully assessed by the application of PROMs. AMT is a surgical approach to manage severe anterior ocular sur- face diseases (AOSDs). AOSDs are related to a damage of the anatomical and physiological features of eye structures - eyelids, tear film, conjunctiva, cornea and limbus. Disabilities associated with AOSDs very often create a vicious circle in which the individual protective mechanisms are not able to compensate and some irreversible processes like squamous metaplasia, cicatrization and vascularization lead to poor quality of life, reduced visual acuity and blindness. On the other hand, prolonged use of topical medications has its adverse effects related to the content of antibiotics, steroids and preservatives $(4,5)$. In such cases, a mediator is needed, on one hand to protect the cornea, to be oxygen-permeable enough, while limiting the penetration and growth of toxic agents and for an anti-inflammatory effect, and on the other hand to stimulate the growth and differentiation of surface cells. Nowadays, an alternative option is called tissue engineering as a part of the regenerative medicine based on the concept of transplantation of exogenous and/or stimulation of endogenous factors and stem cells for the generation of organic substituents and improvement of tissue function. One of the most important components of bioengineering is the support matrix, a role which the amniotic membrane (AM) fulfills. Its qualities are close to the perfect matrix (6-9). The first AMT was documented about 70 years ago. Subsequently, AM was established as a standard for the reconstructive surgery of the ocular surface $(10,11)$. Today AM is widely used for reconstruction of the ocular surface as a treatment of serious corneal diseases such as corneal persistent, recurrent defects, corneal ulcers with or without descemetocele and perforation (12-14), neurotrophic ulcer, microbial keratitis, band keratopathy (15), bullous keratopathy, after photorefractive keratotomy and LASIK, and chemical burns (16). It is used for ocular pemphigoid and the Stevens-Johnson syndrome (17-19). Other indications for AMT include reconstruction of the ocular surface such as conjunctiva surgery with various changes as squamous neoplasia, pterygium, symblepharon, reconstructive surgery of the fornices, stem cells deficit of the limb simultaneously with stem cell transplant, etc. (20). It acts as a "dressing" in various corneal pathologies. The am- 
Yana Manolova, Desislava Vankova, Christina Grupcheva

niotic membrane was recently used as a substrate for culturing limbal stem cells for transplantation.

The indications for AMT are many but the research reports and analysis on AMT and related PROMs are still scarce.

The aim of the study is to present the PROs approach and the created especially for the study PROMs tool. Further on, we aim to summarize, analyze and discuss the PROs data of the study.

\section{MATERIALS AND METHODS Settings and Sample}

The presented PROs prospective study enrolls 306 hospitalized patients diagnosed and grouped into 7 cohorts suitable for AMT. It is a part of a wider research project on AMT. Demographic data and disease-related characteristics were collected in addition to the PROs questionnaire.

\section{Methods}

The PROMs instrument consists of 4 domains and the possible answers are put in ordinal scales. The first domain is Pain, and the possible answers are 4 ( 0 - none, 1 - sometimes mild; 2 - constantly mild; 3 - moderate to severe; 4 - constantly severe). The second domain is Photophobia, and the possi- ble answers are 4 (0 - none, 1 - only at strong light; 2 - at daylight; 3 - at moderate light). The third domain is Secretion and the possible answers are $4(0$ - none, 1 - only tearing; 2 - mucous secretion; 3 - purulent discharge). The fourth domain is Hyperemia and the answers following the Efron grading scale are 5 (grade 0 - normal, grade 1 - trace; grade 2- mild; grade 3 - moderate; grade 4 - severe) (Table 1). Three time points measurement was done: pre-operatively (0 day), on the eighth day after surgery and on the 25th day. Patients fill in the PROMs instrument to assess subjective symptoms at each visit.

\section{Statistical Analysis}

The data was analyzed with SPSS v.20. To measure the significance, ANOVA on RANKS test with Student-Newman-Keuls Method has been applied and p-value below $0.05 \%$ was considered statistically significant.

\section{RESULTS}

All patients were transplanted cryopreserved AM type of filler or a combination technique (type of filler and coating). The patients were divided into seven cohorts according to their diagnosis. Table 2

Table 1. PROMs instrument for evaluation of the amniotic membrane application for anterior ocular surface reconstruction

Demographic data
1. Sex: $\square$ male $\square$ female $\quad$ 2. Age: ............... years.

Clinical information

3. Diagnosis of the patient:

\begin{tabular}{|c|c|c|c|}
\hline 4. PROs & Pre-operatively & $\begin{array}{l}\text { Postoperatively - } \\
8^{\text {th }} \text { day }\end{array}$ & $\begin{array}{l}\text { Postoperatively - } \\
25^{\text {th }} \text { day }\end{array}$ \\
\hline $\begin{array}{l}\text { 4.1. Pain: } 0 \text { - none; } 1 \text { - sometimes mild; } \\
2 \text { - constantly mild; } 3 \text { - moderate to severe; } \\
4 \text { - constantly severe }\end{array}$ & & & \\
\hline $\begin{array}{l}\text { 4.2. Photophobia: } 0 \text { - none; } 1 \text { - only at strong } \\
\text { light; } 2 \text { - at daylight; } 3 \text { - at moderate light; }\end{array}$ & & & \\
\hline $\begin{array}{l}\text { 4.3. Secretion: } 0 \text { - none; } 1 \text { - watery; } \\
2 \text { - mucous secretion; } 3 \text { - purulent discharge }\end{array}$ & & & \\
\hline $\begin{array}{l}\text { 4.4. Hyperemia: } 0 \text { - normal; } 1 \text { - trace; } \\
2 \text { - mild, } 3 \text { - moderate; } 4 \text { - severe; }\end{array}$ & & & \\
\hline
\end{tabular}

5. Type of transplantation according to the depth and type of the defect of the cornea:

$\square$ type - patch/onlay

$\square$ type - graft/inlay: $\quad \square$ one-layered $\quad \square$ two-layered $\quad \square$ multilayered

$\square$ type - onlay on burning 
shows the distribution of patients according to their diagnosis.

Pain intensity is one of PROs, which determines the subjective quality of treatment. The results show that in the pre-operative period $75 \%$ of the patients experience moderate and constantly severe pain, while in the postoperative period the pain is significantly reduced as early as on the $8^{\text {th }}$ day and persists until the $25^{\text {th }}$ day $(\mathrm{p}<0.001)$ The results of the effect after transplantation of AM on the $25^{\text {th }}$ day show a significant reduction (over 60\%) of pain in all cohorts of patients $(\mathrm{p}<0.001)$. A maximum effect is observed in patients with postsurgical keratitis, with a reduction of pain with over $95 \%$. Patients with virus keratitis follow them and then the cohort of patients with relapsed defects and those with neurotrophic ulcers (Figure 1).

While assessing photophobia, which is the second most important subjective factor for the patients, we take into consideration the significant difference in the pre-operative and postoperative period ( $\mathrm{p}<0.001$ ). In the pre-operative period patients primarily complain of photophobia during daylight hours and in moderate illumination. Due to AMT on the 8th and 25th postoperative day they experience photophobia only in strong light. At the end of the studied period more than half of the patients reported absence of photophobia in the cohorts with postoperative keratitis - $83 \%$, other diagnoses - $69 \%$, bacterial keratitis - $67 \%$ and viral keratitis - 59\%. In the other cohorts photophobia was reported only in strong light (recurrent and persistent corneal defects - $62 \%$, injuries and burns - 58\% and neurotrophic ulcers - 43\%) $(\mathrm{p}<0.001)$.

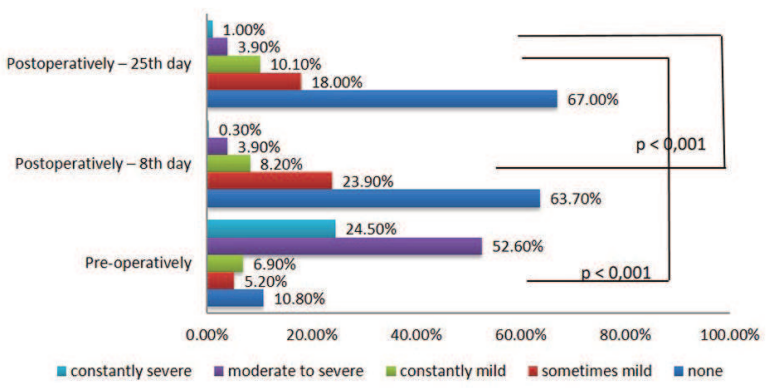

Fig. 1. Pain intensity improvement related to AMT. Preoperative and postoperative assessment on the $8^{\text {th }}$ and $25^{\text {th }}$ day: 0 - none, 1 - sometimes mild, 2 - constantly mild, 3 - moderate to severe, 4 - constantly severe

Secretion is another sign with subjective reflection. The results show that there is a significant difference in the patients' sensation in the preoperative and postoperative period $(\mathrm{p}<0.001)$, and between the sensation on the $8^{\text {th }}$ and the $25^{\text {th }}$ day after transplantation of AM ( $\mathrm{p}<0.001)$. In the preoperative period, more than $60 \%$ of the patients

Table 2. Description of the sample according the diagnosis

\begin{tabular}{c|c} 
DIAGNOSIS & NUMBER OF \\
PATIENTS
\end{tabular}

1. Corneal persistent, recurrent defects:

66

Epithelial basement membrane dystrophy

Macular dystrophy

Peripheral ulcerative keratitis

Band keratopathy

Keratoconus

Keratoglobus

Corneal ulcers

2. Postsurgical keratitis:

Postoperative dellen (after pterigium)

Postoperative after LASIK

After PKP

Bullous keratopathy

3. Neurotrophic ulcers

$\begin{array}{rr} & 38 \\ & 72 \\ \text { Trauma } & 42 \\ \text { Burns } & 30\end{array}$

5. Others:

Necrotizing scleritis Symblepharon

After Tu conjunctivae

Steven-Johnson toxic epidermal necrolysis

Others

6. Bacterial keratitis

7. Viral keratitis:

$$
\text { Postherpetic }
$$

After adenoviral keratoconj unctivitis
19

\section{1}

9

3

9

6

1

17

30

2

5

5

18

38

72

3

2

1

3

10

30

51

33

18 
Yana Manolova, Desislava Vankova, Christina Grupcheva

experience tearing and mucus, most affected in the cohort of bacterial keratitis. On the $8^{\text {th }}$ day only $19 \%$ of all cohorts report such symptoms, and on the $25^{\text {th }}$ day only $9 \%$ experience tearing or the symptom is missing. The bacterial keratitis cohort is the one affected the most in regard to this symptom. On the $25^{\text {th }}$ day there are patients from all cohorts who still have pyogenic secretion, $15 \%$ in the cohorts with injuries and burns, $6 \%$ in the cohorts with bacterial keratitis and in the other cohorts there are only a few cases $(\mathrm{p}<0.001)$.

Hyperemia (red eye) is the last of the PROs. A moderate and severe form of hyperemia in the preoperative period in more than $80 \%$ of the patients in all cohorts. A tendency towards reduction of the redness in the postoperative period on the $8^{\text {th }}$ day after AMT is reported. For this short postoperative period a significant part of the patients had an average redness, more than $50 \%$ of the cohorts with postoperative keratitis and neurotrophic ulcers had mild redness $(\mathrm{p}<0.001)$. Severe redness occurs in only $4 \%$ of the patients with burns and injuries and the patients with viral keratitis. A lack of redness was diagnosed in two cohorts - $21 \%$ in the cohort with recurrent or persistent corneal disorders and 20\% of patients with viral keratitis. Moderate and severe redness was reported in only $6 \%$ of the patients on the $25^{\text {th }}$ day $(\mathrm{p}<0.001)$.

All the reported and analyzed results indicate that AMT has a positive impact on all the PROs domains for every patient $(\mathrm{p}<0.001)$. This is the first study in our country, which aims to measure the impact of AMT on PROs among a large group of patients with different diagnosis over a seven-year period.

\section{DISCUSSION}

The results of this study demonstrate the important role of PROs and PROMs in the assessment of AMT in severely damaged anterior ocular surface. If chronic and recurrent AOSDs are not treated, there will be long-term pathological consequences for the patients. The inflammatory process leads to symptoms either directly (such as pain) or more indirectly (such as emotional and social problems), and also to long-term anterior ocular surface damage and blindness, which itself leads to symptoms such as pain and to disability.
Based on information gathered by filling out the card during the treatment, it was found that AMT has a strong effect on the subjective symptoms in patients with severe and chronically damaged ocular surface. The long period of research and the inclusion of patients with different diseases is a guarantee for representativeness and comparability of the results with those from the world practice of AMT. When treating eye surface diseases, pain relief is often a key outcome. However, pain cannot be quantified with objective clinical measures; PROMs are the only way to assess patients' subjective experience. In 2014, Stefaniu et al. described the effectiveness of applying AM in bullous keratopathy resulting from pseudophakic, aphakic and transplant rejection. The results of the study showed a lack of bullae within 1-2 weeks after the transplantation, as well as absence of pain, photophobia and tearing. Despite the recurrence of symptoms after the resorption of $\mathrm{AM}$, a positive influence on PROs was reported in $88 \%$ of patients within a 4 -year follow-up period (21). Srinivas et al. (2007) studied the effectiveness of AMT in regard to pain and additional indications in 7 patients (7 eyes) with bullous keratopathy and its role in reference to vision improvement in eyes with visual potential. The average follow-up period was 26.57 weeks. In $100 \%$ of the cases a full effect on pain was reported. In terms of the additional indicators: foreign body sensation, photophobia and tearing improvement were reported soon after the first postoperative day. An improvement in vision in 5 of the 7 patients (71.42\%) was observed. The authors conclude that AMT is an effective alternative treatment of painful bullous keratopathy. Similar results in terms of pain were observed by other authors (22-24). In 2015, Tok et al. demonstrated in 15 eyes of 10 patients with toxic keratopathy after application of a topical anesthetic that the initially conducted conservative treatment was not effective because of the intense pain, persistent epithelial defects and progressive stromal thinning. For that reason the authors performed AMT, which led to a significant improvement in all cases except for two. In another publication in 2015, Sui et al. studied 21 eyes of 20 patients with bullous keratopathy and moderate pain was encountered pre- and postoperatively. They found that, postoperatively, $76 \%$ of the eyes experienced absolutely no pain, 
while others complained of mild pain and $47 \%$ of the eyes remained asymptomatic for 3.6 months. In 2003, Espana et al. describe that they overcame $88 \%$ of the severe pain in the eyes with bullous keratopathy (25). These data suggest that AM plays an essential role in reducing the pain and the other subjective symptoms when the ocular surface has been damaged. In addition to the above-mentioned subjective indicators, AM plays a positive role on the inflammation processes and the hyperemia associated with them. The application of AM has a proven positive effect on the subjective sensation of redness (26). In 2005, Huang et al. showed that with patients with pterygium and AMT, the ocular surface recovers faster than in the cohort without AMT and both the levels of conjunctival hyperemia and the symptoms were lower (27). In 2016, Cheng et al. showed that the use of cryopreserved AM in patients with dry eye significantly affected the hyperemia for about 5 days and relieved the symptoms during the studied period which was four months (28). Our results based on PROs are in line with the published data, as we observed constant significant decrease of the redness upon AMT.

\section{CONCLUSION}

AMT proved to be a surgical method for treating severe anterior ocular surface disease that improves the patients' subjective well-being. The heterogeneity in the disease presentation, analyzed for 7 years pre- and postoperatively further enforces the above-mentioned statement regarding the favorable outcome of AMT in the growing range of AOSDs. The authors, being clinicians and public health researchers, are strong supporters of PROs application due to its patient- or person-centered approach. PROs employment is an effective way to assess the result of any health intervention. PROs have been increasingly recognized as part of the holistic approach to health, a necessary ingredient to comprehensive assessment of the impact of treatment and care. Practically, the PROs approach is a real-life personalized medicine.

\section{REFERENCES}

1. Nightingale F. Notes on hospitals [Internet]. London, Longman, Green, Longman, Roberts, and Green; 1863 [cited 2017 Feb 2]. 244 p.
2. FDA, 2009. Guidance for Industry. PatientReported Outcome Measures: Use in Medical Product Development to Support Label.

3. Donabedian A. Explorations in quality assessment and monitoring: the definition of quality and approaches to its assessment. Vol. 3. The methods and findings of quality assessment measurement and monitoring. Ann Arbor, MI: Health Administration Press; 1985.

4. Fraunfelder FT, Fraunfelder Jr FW, Chambers WA. Drug-Induced Ocular Side Effects: Clinical Ocular Toxicology. Elsevier Health Sciences; 2014. p .425.

5. Honda R, Toshida H, Suto C, Fujimaki T, Kimura $\mathrm{T}$, Ohta T, et al. Effect of long-term treatment with eyedrops for glaucoma on conjunctival bacterial flora. Infect Drug Resist. 2011;4:191-6. doi: 10.2147/IDR.S24250

6. Baguneid MS, Seifalian AM, Salacinski HJ, Murray D, Hamilton G, Walker MG. Tissue engineering of blood vessels. Br J Surg. 2006;93(3):282-90. doi: 10.1002/bjs.5256

7. Young CS, Abukawa H, Asrican R, Ravens M, Troulis MJ, Kaban LB, et al. Tissue-engineered hybrid tooth and bone. Tissue Eng. 2005;11(910):1599-610. doi: 10.1089/ten.2005.11.1599

8. Yang S, Leong KF, Du Z, Chua CK. The design of scaffolds for use in tissue engineering. Part I. Traditional factors. Tissue Eng. 2001;7(6):679-89. doi: 10.1089/107632701753337645

9. Walgenbach KJ, Voigt M, Riabikhin AW, Andree C, Schaefer DJ, Galla TJ, et al. Tissue engineering in plastic reconstructive surgery. Anat Rec. 2001;263(4):372-8. doi: 10.1002/ar.1117

10. Hao Y, Ma DH, Hwang DG, Kim WS, Zhang F. Identification of antiangiogenic and antiinflammatory proteins in human amniotic membrane. Cornea. 2000;19(3):348-52.

11. Kim JS, Kim JC, Na BK, Jeong JM, Song CY. Amniotic membrane patching promotes healing and inhibits proteinase activity on wound healing following acute corneal alkali burn. Exp Eye Res. 2000 Mar;70(3):329-37. doi: 10.1006/exer.1999.0794

12. Prabhasawat P, Tesavibul N, Komolsuradej $\mathrm{W}$. Single and multilayer amniotic membrane transplantation for persistent corneal epithelial defect with and without stromal thinning and perforation. Br J Ophthalmol. 2001;85(12):1455-63. doi: 10.1136/bjo.85.12.1455 
Yana Manolova, Desislava Vankova, Christina Grupcheva

13. Solomon A, Meller D, Prabhasawat P, John T, Espana EM, Steuhl K-P, et al. Amniotic membrane grafts for nontraumatic corneal perforations, descemetoceles, and deep ulcers. Ophthalmology. 2002;109(4):694-703. doi: 10.1016/ S0161-6420(01)01032-6

14. Takano Y, Fukagawa K, Miyake-Kashima M, Tanaka M, Asano-Kato N, Dogru M, et al. Dramatic healing of an allergic corneal ulcer persistent for 6 months by amniotic membrane patching in a patient with atopic keratoconjunctivitis: a case report. Cornea. 2004;23(7):723-5.

15. Anderson DF, Prabhasawat $\mathrm{P}$, Alfonso E, Tseng SC. Amniotic membrane transplantation after the primary surgical management of band keratopathy. Cornea. 2001;20(4):354-61.

16. Meller D, Pires RT, Mack RJ, Figueiredo F, Heiligenhaus A, Park WC, et al. Amniotic membrane transplantation for acute chemical or thermal burns. Ophthalmology. 2000;107(5):980-9; discussion 990. doi: 10.1016/S0161-6420(00)00024-5

17. Tseng SC, Prabhasawat P, Barton K, Gray T, Meller D. Amniotic membrane transplantation with or without limbal allografts for corneal surface reconstruction in patients with limbal stem cell deficiency. Arch Ophthalmol Chic Ill 1960. 1998;116(4):431-41. doi:10.1001/archopht.116.4.431

18. Dua HS, Azuara-Blanco A. Allo-limbal transplantation in patients with limbal stem cell deficiency. Br J Ophthalmol. 1999;83(4):414-9. doi: 10.1136/bjo.83.4.414

19. Tsubota K, Satake Y, Ohyama M, Toda I, Takano $\mathrm{Y}$, Ono M, et al. Surgical reconstruction of the ocular surface in advanced ocular cicatricial pemphigoid and Stevens-Johnson syndrome. Am J Ophthalmol. 1996;122(1):38-52. doi: 10.1016/ S0002-9394(14)71962-2

20. LOP-Amniotic-Membrane-Transplantation.pdf [Internet]. [cited 2016 Jun 23]. Available from: http://ibi-iran.com/wp-content/uploads/2015/07/ LOP-Amniotic-Membrane-Transplantation.pdf

21. Stefaniu G, Chiotoroiu S, Secureanu F, Purcarea V, Zemba M. Use of amniotic membrane in bullous keratopathy palliative care. J Med Life. 2014;7(Spec Iss 2):88-91.

22. Tok OY, Tok L, Atay IM, Argun TC, Demirci N, Gunes A. Toxic keratopathy associated with abuse of topical anesthetics and amniotic membrane transplantation for treatment. Int J Ophthalmol. 2015;8(5):938-44. doi: 10.3980/j. issn.2222-3959.2015.05.15

23. Shimmura S, Shimazaki J, Ohashi Y, Tsubota K. Antiinflammatory effects of amniotic membrane transplantation in ocular surface disorders. Cornea. 2001;20(4):408-13.

24. Thatte S. Amniotic membrane transplantation: An option for ocular surface disorders. Oman J Ophthalmol. 2011;4(2):67-72. doi: 10.4103/0974-620X.83656

25. Espana EM, Grueterich M, Sandoval H, Solomon A, Alfonso E, Karp CL, et al. Amniotic membrane transplantation for bullous keratopathy in eyes with poor visual potential. J Cataract Refract Surg. 2003;29(2):279-84. doi: 10.1016/ S0886-3350(02)01525-0

26. Liang W, Li R, Deng X. Comparison of the efficacy of pterygium resection combined with conjunctival autograft versus pterygium resection combined with amniotic membrane transplantation. Eye Sci. 2012;27(2):102-5.

27. Huang Y, Wang B, Ye Q. [Clinical study in combining application of mitomycin and amnion transplantation together with pterygium resection]. Yan Ke Xue Bao Eye Sci Yan Ke Xue Bao Bian Ji Bu. 2005;21(4):110-3, 123.

28. Cheng AMS, Zhao D, Chen R, Yin HY, Tighe S, Sheha H, et al. Accelerated Restoration of Ocular Surface Health in Dry Eye Disease by Self-Retained Cryopreserved Amniotic Membrane. Ocul Surf. 2016;14(1):56-63. doi: 10.1016/j.jtos.2015.07.003 